\title{
Operationalising Quality Assurance Processes in Tanzanian Higher Education: Academics' Perceptions from Selected Private Universities
}

\author{
Samson John Mgaiwa \\ Faculty of Education, Department of Educational Foundations and Management, Mkwawa University College of Education, \\ Iringa, Tanzania \\ Email: mgaiwa12@gmail.com, mgaiwa@muce.ac.tz
}

How to cite this paper: Mgaiwa, S. J. (2018). Operationalising Quality Assurance Processes in Tanzanian Higher Education: Academics' Perceptions from Selected Private Universities. Creative Education, 9, 901-918.

https://doi.org/10.4236/ce.2018.96066

Received: March 20, 2018

Accepted: May 13, 2018

Published: May 16, 2018

Copyright $\odot 2018$ by author and Scientific Research Publishing Inc. This work is licensed under the Creative Commons Attribution International License (CC BY 4.0).

http://creativecommons.org/licenses/by/4.0/

\begin{abstract}
The purpose of this research was to examine the extent of operationalization of quality assurance processes in Tanzanian Private Universities (PRUs). A descriptive survey design informed by a mixed research approach was employed to guide this research. Purposive and stratified random sampling procedures were employed to select a sample of one hundred and ninety-five ( $\mathrm{N}$ = 195) participants in the study who comprised of 191 academics, and 4 quality assurance officials from four private universities. Questionnaires and face-to-face interviews were used for data collection. The findings indicated that QA processes such as institutional self-assessment and external examinations were to a large extent conducted by PRUs. Unlike these findings, internal quality audits and tracer studies were not adequately carried out. Conclusively, the non-regular practice of these processes remains the main challenge in most of the surveyed Tanzanian PRUs because they are stipulated in the institutional policy documents without a will to adequately implement them.
\end{abstract}

\section{Keywords}

Quality Assurance, Self-Assessment, Examinations, Audit, Private Universities

\section{Background}

Higher education has a significant contribution to social, political, economic, and technological development. As such, the criticality of education is dependent on its quality. In an era of increased globalisation, quality of higher education has become the focus of every country's strategic plans to enhance competitiveness and to meet international expectations and standards (OECD, 2012). It 
is from this reality, the quality of service or product, such as education provision, is universally acknowledged as a factor for successful business (Adelabu \& Akinwumi, 2008; Allais, 2009; Balen, 2010; Kuhanga, 2006). The growth of Private Universities (PRUs) in the World and Tanzania in particular like in many countries of the world is phenomenal. The Private Universities (PRUs) have increased tremendously all over the world with diverse programmes in offer. Its contribution to the expansion and access of higher education to students is irrefutable. In Tanzania, all universities including private universities are governed by Universities Act of 2005 under the supervision of the Tanzania Commission for Universities (URT, 2005; Ishengoma, 2007). However, some private universities in Tanzania like in some countries especially developing ones are allegedly violating this Act. This situation has made quality of education in Tanzanian Private Universities (PRUs) to be a topical issue among scholars, quality assurance stakeholders and even ordinary citizens (Simon, 2010; Ishengoma, 2007). The rapid increase of private higher education providers in recent years has raised more questions on the quality of education services in these institutions. This has prompted institutions and government to put in place various forms of quality assurance mechanisms as an attempt to be an oversight agent to monitor quality of education and to regulate the providers (Materu, 2007; Ishengoma, 2007; Varghese, 2009).

Historically, before the introduction of liberalisation policies in the late 1980s, the government of Tanzania was the sole provider of university education since independence. The University of Dar es Salaam and Sokoine University of Agriculture by then were the only institutions providing higher education in the country; and were growing slowly (Matimbo, 2002; Kuhanga, 2006; Ishengoma, 2007). Despite having these universities, Tanzania was still lagging behind compared to other Sub Saharan African countries in terms of participation rate, number of universities and social economic and political development in general (Materu, 2007; Varghese, 2009). It was against this background and the rapidly increasing social demands and needs for university education. Policy measures had to be taken to involve the private sector in the provision of higher education in Tanzania. The role of the state was to provide enabling environment through legislation. This was in line with what went on in all other sectors and the global trends of neoliberal economic, social and political liberalization.

The commitment of the government of Tanzania in assuring and controlling the quality of higher education in the country was first signified in 1995 when the government established the then Higher Education Accreditation Council (HEAC). This new institutional organisation was charged with a responsibility to register and accredit Private Universities in the country. HEAC was replaced by the Tanzania Commission for Universities (TCU) in 2005 (TCU, 2012a). The commission is a corporate body charged with responsibilities of overseeing and controlling quality by evaluating and approving the quality of infrastructure, setting criteria for recruiting academic and research staff, academic programmes, 
setting student admission criteria, assessment of students, grading system, classification, and recognition of awards (URT, 2005). These quality control mechanisms are used across universities and university colleges regardless of their ownership (Mgaiwa \& Ishengoma, 2017). The Commission has already put in place regulations to guide the conduct of universities and university colleges and ensure that no university compromise the quality of education provided. To that end, universities are required to have proper measures for quality control and assurance. So far, there are no empirical studies establishing the extent to which the PRUs conform to and maintain quality standards in the provision of higher education in Tanzania. Some evidences suggest that some PRUs are not complying with regulations. For example, of recent the TCU revoked the earlier approval that established the two constituent College of St. Joseph university of Tanzania for non-compliance with law hence providing education below the required standards (Kolumbia, 2016). In a similar vein, some degree programmes have been established without meeting pre-requisite requirements such as number of qualified academics (Mgaiwa \& Poncian, 2016).

\subsection{Quality Assurance in Higher Education: A Review}

A recent observation in Africa shows that private universities constitute a second type of universities in relation to public universities. There is some evidence that PRUs are a fast expanding segment of higher education today in Africa (Levy, 2007; Varghese, 2004; Mgaiwa \& Ishengoma, 2017). The expansion of PRUs in Africa is characterised by junior academics with limited experience on the job coupled with the teaching load of up to 20 hours in a week (Ajayi, \& Akindutire, 2007; Materu, 2007). Furthermore, academics in private universities stay for only short period before moving on to their "real" jobs in public universities which provide job security and prestige (Banya, 2001). Varghese (2004) asserted that, private universities operate with a limited number of academic staff and rely too much on part-timers. In fact, there are also instances where some private universities operate without even a single regular staff (Varghese, 2004). At times some of the private universities in Africa are headed by senior professors from public universities. The inadequacy of qualified academics in these universities implies that the quality of their academic programmes offered by these institutions is also questionable. This is because the absence of qualified academics undermines the quality of teaching, research and delivery of community services.

Evidence from Africa shows that there are common institutional quality assurance processes in most private universities. For example, institutional self-assessments, external examinations (peer reviews), tracer studies, exit surveys, and quality audits. These QA processes are common to both private and public African universities because some of them are used by National commissions for accreditation and reaccreditation. Okebukola and Shabani (2007), argue that the quality assurance practices in African private universities are applied in the same manner and rigour as in public universities. However, this ar- 
gument does not apply to all universities because, universities in Africa exists in relatively similar but different and diverse environments that make them to have also relatively different quality assurance mechanisms. For example, Mgaiwa and Ishengoma (2017), established that, Tanzanian private universities suffer fiscal resources than public universities to the extent of affecting compliance to quality assurance processes set by TCU.

The growth of private universities in Africa and beyond as presented elsewhere in this paper has had diverse effects to the sector of higher education. For example, the community is celebrating the rapid expansion of higher education provision due to increased access as well as diversification in the types of programmes in both conventional and distance learning. Nevertheless, the expansion of the subsector has heightened the existing concern about the quality of higher education provision (Kuhanga, 2006; Thaver, 2006; Varghese, 2006). This has been the outcry of many developing countries. For example, many countries in the world today, have instituted organisations or boards, committees and agencies charged with the responsibility of assuring, maintaining, and enhancing the provision of quality education in their Higher Education systems (Levy, 2007; Varghese, 2004; Varghese, 2009). The agency for quality higher education has and internationalization of higher education have pushed many regions to have established continental and regional quality assurance agencies to safeguard and maintain standards of the education provided. Including many other reasons, this is among the reasons for establishment of Association for African Universities (AAU) and Inter-University Council for East Africa (IUCEA) in 1967 and 1990 respectively (Nkunya, Bienefeld, \& Hansert, 2009; Mgaiwa \& Ishengoma, 2017). Quality assurance agencies in African higher education started to emerge in 1960s and became popular in 1990s and the co-operation at the regional level has been growing in recent years. The AAU set up the first pan-African network for quality assurance in 2009, which was an important step towards enhancing quality assurance on the continent (Levy, 2007).

A good deal of research indicates that in East Africa, the Inter-University Council for East Africa (IUCEA) was established and mandated to promote and support the strategic development of higher education and research in the East African Community (EAC) partner states through networking of university institutions in the region (Nkunya, Bienefeld, \& Hansert, 2009). The IUCEA operates under an Act of the East African Legislative Assembly which mandates the IUCEA to work with national higher education commissions/councils to establish a regional quality assurance framework. Between 1990 and 2007 there was a proliferation of universities from 100 to 200 public universities, and from 24 to 428 private universities in the region respectively (Varghese, 2009). This surge of universities with seventeen years raises concerns over quality of education provided in these universities. Hence calling for a need of having a strategy of avoiding compromising quality in education by instituting appropriate regulatory systems. In this regard, the East African quality assurance framework was 
put in place to strengthen higher education in East Africa by enabling member universities to participate in cross-border education in and outside East Africa; setting common higher education quality standards for universities; promoting and safeguarding comparability and compatibility of higher education quality assurance standards in East Africa and with outside world; promoting graduate labour mobility regionally/internationally; and promoting uniform regional higher education benchmark standards based on international practices (Ishengoma, 2007).

Similarly, Tanzania established the Higher Education Accreditation Council (HEAC) in 1995 which was later replaced by the Tanzania Commission for Universities (TCU) in 2005. The TCU was charged with the responsibility of overseeing and controlling the quality of education in universities and university colleges along with ensuring that these institutions conform to their pre-determined standards approved by the commission. The commission has already put in place regulations to guide the conduct of universities and university colleges to ensure that no university was reduced to a degree mill (Ishengoma, 2007; Mgaiwa \& Ishengoma, 2017).

A body of literature indicates that quality assurance processes are critical to institution such as universities. This is because, it offers way for verifying objective evidence of processes, assessing how successfully processes have been implemented, judging the effectiveness of achieving any defined target levels and providing evidence regarding elimination of problem (Becket \& Brookes, 2005; Andy \& Parker, 2008; Allais, 2009). Other quality processes such as quality audits have been credited for offering transparency, learning, enhanced status of work and social integration at the "grass-root" level (Brennan \& Shah, 2000; Stensaker, 2008; Ursin et al., 2008; Haapakorpi, 2011).

\subsection{The Objectives of the Study}

University accreditation in Tanzania is normally done when the institutions have satisfied the QA processes such as institutional self-assessment, internal audits and external examinations and submitted the report of the same to the Tanzania Commission for Universities. The assessment of the commission on compliance of the criteria above enables it to provide a quality label to the respective institutions. The quality label can either be provisional or full registration; accreditation and chattering conferred by the President of the United Republic of Tanzania (Ishengoma, 2007; TCU, 2012a). Accreditation is one of the highest and accepted quality label provided by the TCU. Despite the existence of the TCU provisions that require universities to conduct QA processes at institutional level, only 9 out of 35 PRUs which is equivalent to 25 percent of PRUs were accredited as of $30^{\text {th }}$ September 2016. Most of PRUs have remained with provisional and full registration status (TCU, 2016). Besides, in 2016 two constituent colleges of St. Joseph university of Tanzania faced government barn of their establishment for not meeting the requisite requirements for degree offer- 
ing following alleged non-compliance and offering education below the required standard (Kolumbia, 2016). It is against this background that it was considered important to find out whether or not and how PRUs conduct internal institutional quality assurance and control processes. Therefore, the objective of the study was to examine the extent to which PRUs operationalize institutional quality assurance and control processes in Tanzania.

\section{Methodology}

\subsection{Study Design}

This research was conducted within a descriptive research design under mixed research approach. Given the nature of data collected in the present research, the use a mixed methods design was adopted. Both quantitative data and qualitative data were collected concurrently for methodological triangulation and complementarity so as to offset the weaknesses inherent within methods. Scholars argue that descriptive survey relies on a large-scale data gathering from a large number of people so as to be able to make generalizations on given facts or variables (Thomas, 2009; Greener, 2011; Yin, 2011). The design was also chosen on the ground that it would enable the researcher to summarize the responses of different groups of respondents and be able to collect their perceptions and opinions on whether or not institutional QA processes are conducted in PRUs. The design was further adopted due to its ability to enable the researcher to collect multi-sourced data using various methods from a wide population in a short period of time.

\subsection{Study Site and Sample}

The study was conducted in four out of fifty-six private universities and university colleges in Tanzania. These universities included Ruaha Catholic University, Muslim University of Morogoro, St. John's University of Tanzania and St. Augustine University of Tanzania. The researcher employed purposive and stratified simple random sampling techniques in selecting the universities, academic staff and quality assurance officials. The universities were purposively selected to represent the four major zones in the country and to have a mixture of both old and new ones with different ownership. Similarly, Quality Assurance officials were purposively selected by virtue of their positions, and therefore they were thought to possess credible and reliable information regarding the study in question. On the other hand, stratified random sampling was used to select academic members of staff. In this regard, the respondents were chosen based on their merits and the roles they play in monitoring QA processes in their respective PRUs. Nevertheless, in order to obtain an acceptable and representative sample size for this study the researcher adopted a formula from Yamane (1967) as cited in Israel (1992) that is used to calculate sample size in survey studies of population which is in proportions. In the formula, the researcher chose to use $95 \%$ confidence level and.05 as a precision level. Yamane's formula for calculat- 
ing survey sample size in proportions is:

$$
n=\frac{N}{1+N(e)^{2}}
$$

where $n$ is a sample size, $N$ is total target population, $e$ is level of precision.

Therefore, with the total target population of 632 academic staff, a total of 191 academic staff sampled through a stratified random sampling technique, and 4 quality assurance officials who were purposively selected making a grand total of 195 respondents were sampled (Table 1).

\subsection{Data Collection Techniques}

Close ended questionnaires and face-to-face interviews were used in data collection. The questionnaires items focused on the QA processes at institutional level which included institutional self-assessment, external examinations, internal quality audits and tracer studies. The questionnaires were preferred for data collection in this research because it was appropriate for collecting quantitative data and it could be easy to administer to a good number of respondents who respond in private settings. Besides, the questionnaires could increase the degree of anonymity among respondents while minimizing the element of bias because of the privacy secured in filling them. The questions prepared in questionnaires demanded YES or NO responses and were administered to 191 academics from the four PRUs under the study. The nature of this study made the questionnaire an appropriate data collection tool as it enabled the researcher to find out whether PRUs conduct QA processes at the institutional level. As key players in the QA processes at the institutional level, the members of academics were able to provide valuable information.

Qualitative data were collected through face-to-face, unstructured interviews. This technique was deemed appropriate in this research because of its flexibility as it enabled both the researcher and respondents to get in-depth/adequate information, clarifications and follow up questions on perceptions held by QA officials on QA processes in Tanzania PRUs. The information was collected from four QA officials as they were thought to have reliable and an insider information regarding QA processes. QA officials were to reveal how QA processes in their respective PRUs were conducted. However, their views were weighed against those of the academic staff to crosscheck for the authenticity of information provided.

This research established content validity of instruments during the designing

Table 1. Summary of population and sample size of the studied PRUs.

\begin{tabular}{ccccc}
\hline Category & Total Pop. & Expected sample size & Actual sample size & As a \% of expected sample \\
\hline Academic staff & 632 & 244 & 191 & $78 \%$ \\
QA officials & 4 & 4 & 4 & $100 \%$ \\
Total & 636 & 248 & 195 & $78.6 \%$ \\
\hline
\end{tabular}


stage and in the field. During the designing stage, the researcher distributed the interview questions and the questionnaires to his fellow academics (expert review) so as to get their feedback. Before the actual field work, the data collection instruments were subjected to a pilot study at Hubert Kairuki Memorial University (HKMU), a private university. A total of 70 academics were involved in the pilot study. Modifications were made including rearranging the questions, deletion and addition of some questions where it was deemed necessary. The process of ensuring validity was done in line with the argument that validity determines whether the research instruments truly measure what they are supposed to measure or how truthful the research results will be (Creswell, 2009; Thomas, 2009).

\subsection{Data Analysis Procedures}

Data analysis was an on-going process throughout the data collection phase and thereafter. The data collected were sorted and placed in their respective categories in accordance with the study objectives. The researcher then analysed quantitative data obtained through questionnaire with the help of the Statistical Package for Social Sciences (SPSS) Version 20.0 to generate frequencies and percentages of the data. The frequencies and percentages were organised into tables and graphs. On the other hand, data collected through interviews and documentary reviews were subjected to thematic analysis. Thematic analysis allowed for the analysis of qualitative data on the basis of relevant themes. In this study, thematic analysis involved six major stages: familiarisation with data, generating initial codes, searching for themes, reviewing themes, defining and naming themes and producing the report (Greener, 2011; Yin, 2011). Thematic analysis used for qualitative data was preferred because it also simplified interpretations of the data presented largely in narrative and descriptive form.

\section{Findings and Discussion}

The objective of this research was to examine the extent to which and how Tanzanian PRUs conduct quality assurance and control processes at institutional level. The studied QA processes at institutional were: institutional self-assessment, external examinations, internal quality audits and tracer studies. These processes were studied because they are legal and need to be complied by all universities registered by the Tanzania Commission for Universities (TCU, 2015). To obtain the requisite data to address this objective, closed ended questionnaires were administered to 191 academics and face-to-face interviews with four quality assurance officials. The findings are presented in the subsections that follow based on each attribute of the QA process.

\subsection{The Institutional Self-Assessment}

Through questionnaires, the academic staff were asked to give out their perceptions on whether or not institutional self-assessment were carried out in their 
respective universities. The responses were measured by the YES or NO and Not Sure responses. In this question two attributes were examined; the first was about whether or not institutional self-assessments were being carried out; whereas the second attribute was to find out if the process was conducted regularly. The practice of regularity of institutional-self assessment is in five years interval for all institutions. The responses to these attributes are presented in Table 2 in form of frequencies and percentages.

Findings indicated that 171 (89.5) percent of the total participants responded YES, implying that institutional self-assessments were carried out in most studied Tanzanian PRUs while only 8 (4.2) percent responded NO implying that, institutional self-assessment were not carried out. The other 32 (17) percent were unaware on whether institutional self-assessments were being carried out. This suggests that quality assurance practices are not adequately communicated to staff or there is little quality culture to staff. In view of these findings, it appears that institutional self-assessments were adequately conducted in the surveyed PRUs. Similarly, the findings obtained through questionnaires were in line with the data obtained through face to face interviews from QA directors and coordinators in the surveyed PRUs. The QA directors and coordinators informed that institutional self-assessments were conducted by their respective private universities. To confirm this, one of the QA directors had the following to say:

Yes, certainly, as an institution I would say we do in the sense that since the establishment of the directorate in 2009 we have conducted it twice, one was under pilot study known as African Catholic Universities Quality Assurance Agency (ACUQAA). The second one is underway as the report is not yet out, and actually this is a preparation for reaccreditation by TCU. Normally we conduct self-assessment at departmental and programme level and eventually we compile a single report to TCU for reaccreditation as per requirement (QA director, University A).

These findings are in consonance with observation by Idobo (2009) who observed that in recent years, self-assessment in some African countries like Nigeria and South Africa is done as a preparation for accreditation and institutional assessment. This shows that PRUs through self-assessment evaluate the university

Table 2. Staff perceptions on the conduct and regularity of institutional self-assessment in Studied PRUs.

\begin{tabular}{ccccc}
\hline \multirow{2}{*}{ Respondents Responses } & \multicolumn{2}{c}{$\begin{array}{c}\text { Practice of Self-Assessment } \\
\text { N \% }\end{array}$} & \multicolumn{2}{c}{$\begin{array}{c}\text { Regularity of Self-Assessment } \\
\text { N \% }\end{array}$} \\
\hline Yes & 171 & 89.5 & 47 & 24.6 \\
Not Sure & 12 & 6.3 & 32 & 16.8 \\
No & 8 & 4.2 & 112 & 58.6 \\
Total Responses & 191 & 100 & 191 & 100.0 \\
\hline
\end{tabular}

Source: Field Data. 
objectives to examine the extent of their goal achievement while adhering to TCU regulations. Based on these findings it may be argued that PRUs are in position to identify their weaknesses and strengths in providing education services if the process is credibly conducted. However, conducting institutional assessment is one thing and determining effectiveness of such a process is another thing. This is reflected in the findings which show that institutional self-assessments were conducted in PRUs. Such findings are quite different from what has been documented by TCU. Evidences show that only 5 (17) percent of registered Tanzania PRUs were accredited up to 2012 (TCU, 2012b). Arguably, this suggests that PRUs are conducting institutional self-assessment because it is a pre-requisite for accreditation. However, evidence collected through interviews from the studied PRUs indicated that although the process of conducting self-assessment was done to a greater extent, little attention is paid to taking corrective measures to identified weaknesses. For example, during interview one of the QA coordinator had the following to say when he was asked a follow up question as to what they do with weakness identified during self-assessments.

"You know sometimes it is take time to take corrective measures due to lack of funds. However, that is not an excuse to compromise quality, we do what is within our budget reach" (QA coordinator from university "C")

Regarding whether or not institutional self-assessments were carried regularly, the findings revealed that majority of the respondents 112 (59) percent of the total responded NO implying that the process was not regularly carried out. On the other hand, 47 (24 percent) responded YES institutional self-assessment were carried out regularly. Therefore, these findings suggest that, to a larger extent, institutional self-assessments were not conducted regularly in PRUs. When QA officials were asked as to why they were not conducted regularly, most of them (3 of 4) gave responses that the process was hampered by inadequate funding. The literature has identified that the PRUs mainly depend on students' fees as a major source of funding which has never been sufficient to cover institutional activities (Ishengoma, 2008). Such dependency on students' fees as a source of finance appears to compel PRUs not to conduct self-assessments on a regular basis as per requirement of the TCU. Arguably, this in turn can affect the quality of education provided by PRUs as the amount collected from fees is not only reliable but also unsustainable.

\subsection{External Examinations}

With regard to external examination attribute, respondents were asked to indicate whether or not their institutions were conducting external review of university examinations as well as the regularity of such process. The mode of response was in form of YES or NO and NOT SURE responses. Figure 1 indicates the academic staff responses on whether PRUs were conducting external examinations and its regularities.

In responding to the question on whether PRUs conducted external examinations, 


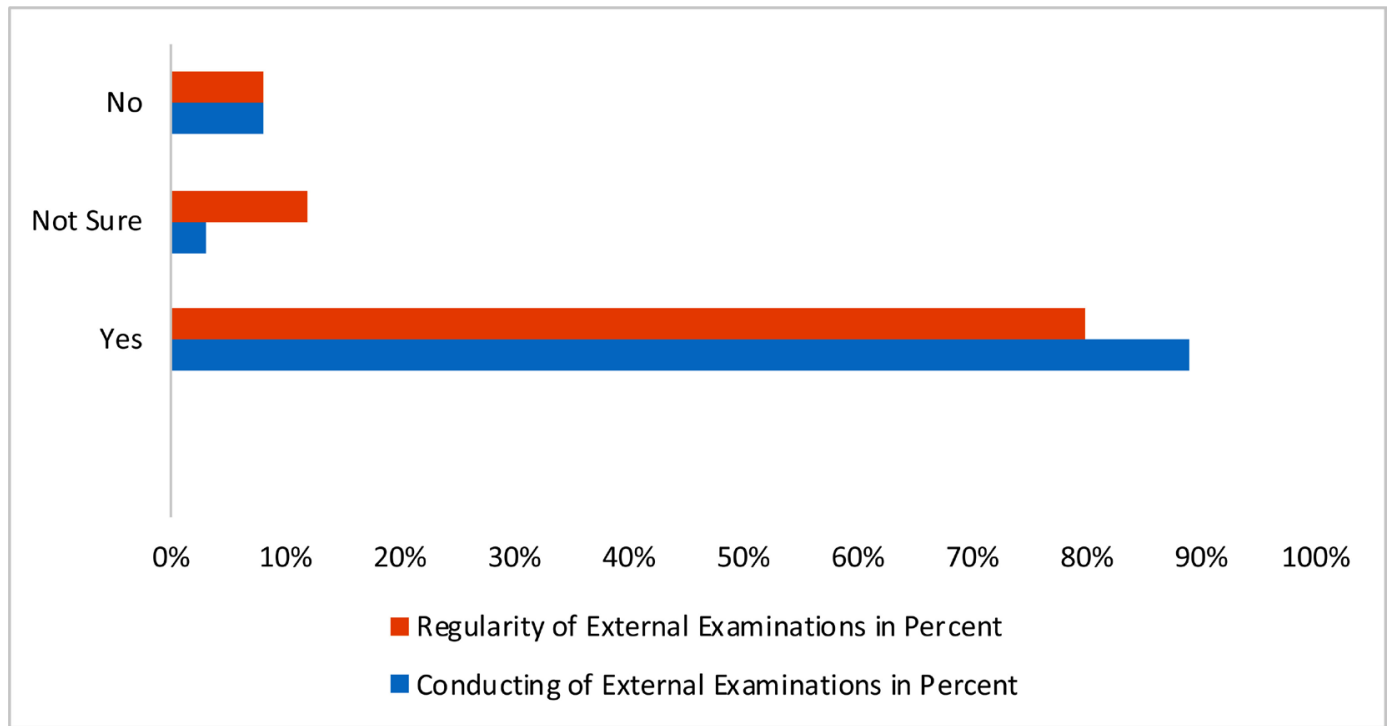

Figure 1. Staff perceptions on the conduct and regularity of external examinations in PRUs.

findings revealed that 89 percent of the total respondents said YES meaning that, external examinations were conducted. On the other hand, 8 percent of the total respondents responded No implying that, the surveyed PRUs were not conducting external examinations. Based on those who responded YES, it is clear that PRUs were to a large extent perceived to be conducting external examinations. Regarding the regularity of the external examinations, 79 percent of the respondents said YES, meaning that external examinations were carried out regularly. Nevertheless, 8 percent of the total respondents were not sure whether external examinations were carried out regularly. This observation tallies with data obtained through interviews from quality assurance officials who confirmed that PRUs in Tanzania conduct external examinations and the process is carried out regularly. To cement on this, QA coordinator from university " $\mathrm{M}$ " during interview, when answering the question how his institution conducts external examinations, had the following to say:

External examination is one of the best practices we do to ensure that examination process is not only fair and credible but also sound for academic awards that are offered by a university. Look...actually we do it and we do in every semester. ... what we actually do is to invite external examiners from other universities who go through our examinations and students' scripts. After all that, he/she writes a report that shows the strength and weakness of our examination process and advise us on how to make improvements through recommendations that we share through our respective departments (QA coordinator, University $\mathrm{M}$ ).

These findings are in line with the observations of Allais (2009) who observed that, the culture of conducting external examinations is normally that of checking the question papers, as well as a sample of the students' scripts from one university by an expert in the same field from a different university. External 
examiners also provide comments on the standard of the courses which are taught. Since majority of the respondents, 89 percent, suggest that external examinations were conducted to a larger extent, this implies that, external examiners have managed to help PRUs maintain academic standards (compliance). The findings further show that the process has been able to verify the appropriateness of the awards which the external examiners are appointed to examine and that assessments are always sound, fair and are in line with the institutions' policies and regulations.

Despite the fact that findings show that external examinations were being conducted, there is some feeling that the quality of graduates from PRUs appears to be questionable (Babyegeya, 2007; Ishengoma, 2007; Mgaiwa \& Ishengoma, 2017). Arguably, this may be suggesting that the process is not carried out effectively or there are other factors other than external examination process because quality of graduates depends on many other factors. Indeed, the effectiveness of these processes and the qualities of external examiners are critical in conducting external examinations on regular basis. Regarding whether external examinations were regularly conducted, findings indicated that 79 percent of total respondents responded YES. Surprisingly, these findings were somehow contradictory to those obtained from the interviews. Basically, external examination exercise is supposed to be carried out in either semester basis or in each academic year. During interviews, some quality assurance coordinators and directors reported that sometimes they do not conduct external examinations on regular basis or in all courses due to poor financial capacity experienced by PRUs. "This is a costly process especially when foreign external examiners are used or invited" said one of the QA coordinator from university B. This assertion is also supported by Okebukola and Shabani (2007) who found that due to cost of external examinations being unmanageable, some universities in Sub Saharan Africa fail to conduct external examinations on regular basis. Arguably, this implies that it is possible that some PRUs due to financial constrains have not managed to bear the cost of conducting external examinations on regular basis. The cost of external examinations has also tempted some public universities to change the interval of regularity of external examinations. For example, the university of Dar es Salaam which is a country's flagship have reformed the interval of external examinations from being annually to once in every three years. This paper argues that external examination is something that needs to be conducted on a closer and regular basis and technically in annual basis so that, grades of courses offered are fair and sound to reflect competencies learned and student's abilities.

\subsection{Internal Quality Audits}

In this attribute, respondents were asked about two aspects; one was about whether PRUs conduct internal quality audits and the second was whether internal quality audits were conducted on a regular basis. In principle, quality au- 
dits are supposed to be carried out in every five years. The responses were in form of YES or NO and NOT SURE. Regarding whether internal quality audits were conducted and the regularity with which they were conducted, findings are summarised in Table 3.

From Table 3, the findings indicate 74 percent of the total respondents said NO implying that internal quality audits were not conducted in their respective PRUs. On the other hand, 17 percent indicated YES to mean that internal quality audits were being conducted and 34 percent of the total respondents were not sure whether quality audits were conducted or not. The findings suggest that, the authorities responsible for monitoring of quality issues in universities have not been able to ensure universities are accountable for not complying with legal obligations. The findings are also similar to what happened in Finland before 2010 where audits were weak, and its system resembles that of Tanzania where audits are a form of certification (Haapakorpi, 2011). Similarly, during interview with QA coordinators and directors, most interviewees reiterated that internal quality audits were not conducted. When they were asked to give the reasons as to why quality audits were not conducted, the major reason given was that internal audits have been replaced by external examinations.

When you have external examination in a university, the internal quality auditing process becomes useless as the weakness that could be identified by internal auditor can easily be identified by external examiner (QA Director, University A).

The above quotation of a quality assurance director implies that QA directors and coordinators in PRUs lack understanding of what quality audits mean in a university. Quality audits go beyond what external examination processes do as it makes a full assessment of a university or programmes (Andy \& Paker, 2008; Allais, 2009; Haapakorpi, 2011). In the same vein, Hayward (2006) argues that audit process involves a review of an institution or programmes to determine if its curriculum, staff and infrastructure meet the standards. Furthermore, the respondents were asked to indicate if internal quality audits were conducted on a regular basis. Findings revealed that 78 percent of the respondents who responded YES disagreed by saying NO. On the other hand, 2.5 percent of the total respondent agreed by saying YES while the rest were not sure, meaning that

Table 3. Staff perceptions on the conduct and regularity of quality audits in PRUs.

\begin{tabular}{ccccc}
\hline $\begin{array}{c}\text { Respondent } \\
\text { Responses }\end{array}$ & $\begin{array}{c}\text { Practice of } \\
\text { Quality Audit }\end{array}$ & $\begin{array}{c}\text { Quality Audit } \\
\text { in Percent }\end{array}$ & $\begin{array}{c}\text { Regularity of } \\
\text { Quality Audit }\end{array}$ & $\begin{array}{c}\text { Regularity of Quality } \\
\text { Audit in Percent }\end{array}$ \\
\hline Yes & 17 & 8.9 & 5 & 2.6 \\
Not Sure & 33 & 17.3 & 34 & 17.8 \\
No & 141 & 73.8 & 152 & 79.6 \\
Total Responses & 191 & 100.0 & 191 & 100.0 \\
\hline
\end{tabular}

Source: Field Data. 
quality audits were being conducted. Logically, if the findings indicated that internal quality audits were not conducted, regularity of internal quality audits could not be an issue of discussion.

Based on the findings, it can be argued that PRUs which do not conduct internal quality audits are likely to be unaware of how far they have managed to achieve their stated goals and comply with quality management systems; and to what extent they have managed to eliminate or reduce problems related to quality systems at institutional level.

\subsection{Tracer Studies}

The main theme in this attribute was to assess whether PRUs have a culture of conducting tracer studies and the regularity of such a process. The idea behind this process is to get feedback from former students and adjust training as per feedback sought. The aggregate response results are presented in form of YES or NO in Figure 2.

The results from academics who filled out the questionnaires as presented in Figure 2 revealed that 55 percent of the respondents disagreed by responding NO. Besides, 23 percent of the total respondents agreed by responding YES, meaning that tracer studies were conducted. In connection with the practice, respondents were also asked to tell whether or not tracer studies were conducted on a regular basis. The findings in this question indicated that 72 percent of the total respondents disagreed by responding NO while 8 percent agreed. However, 19 percent had no response. Therefore, it is clear that to a large extent, (72 percent) of the total respondents from surveyed PRUs did not conduct tracer studies. These findings are also in line with information obtained through interviews in which three QA officials out of four reiterated that they had never conducted tracer studies since the establishment of their institutions. For instance, one of

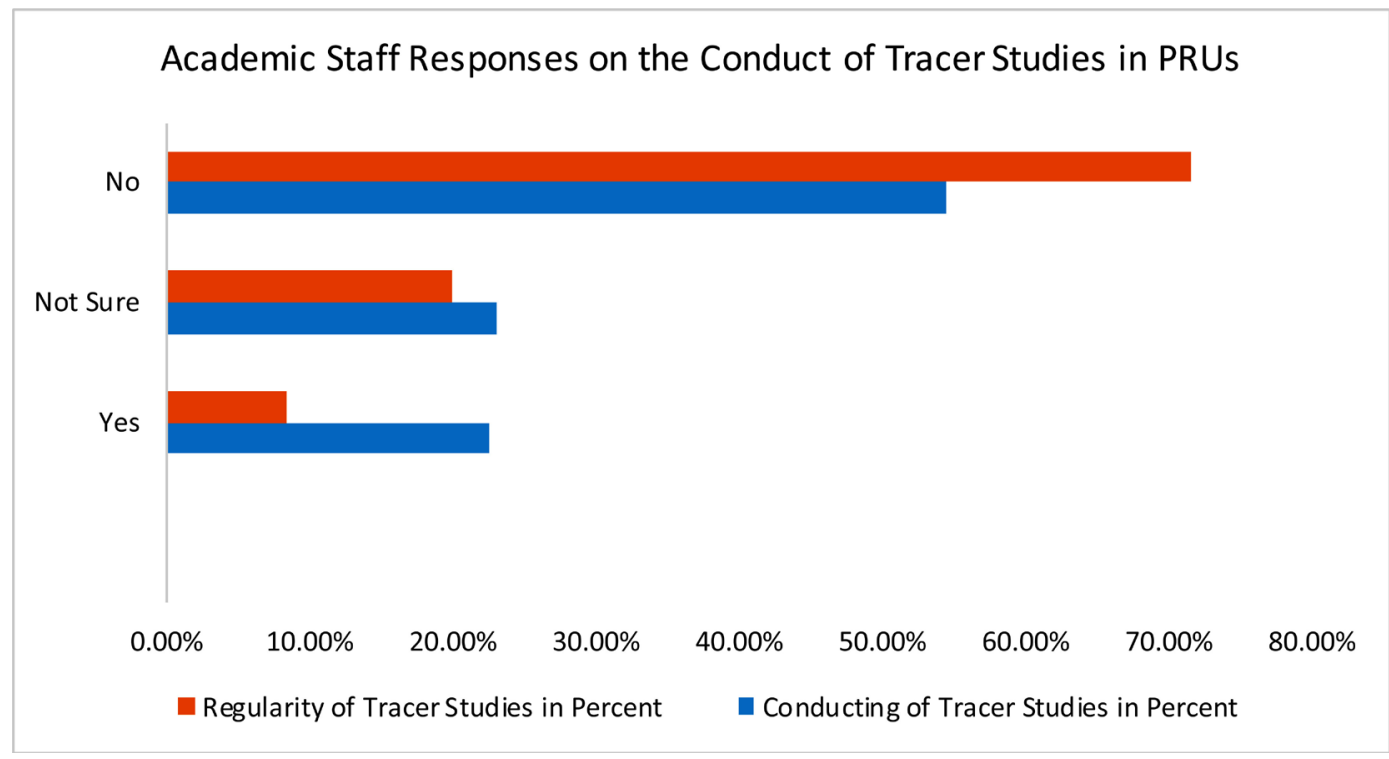

Figure 2. Staff perceptions on the conduct and regularity of Tracer studies in PRUs. 
the QA directors asserted that:

You see... because maybe we are just developing, and we are not old like other universities in the country, so our departments are not prepared to carry out tracer studies. But with the introduction of QA directorate some of the departments now are realising that there is a great need of conducting tracer studies. That is why business school expects to conduct a tracer study in order to take a look on labour needs. I think if you want to conduct tracer studies you need a certain level of capability which I think we are lacking (QA director, university C).

The foregoing quotation implies that most PRUs were not conducting tracer studies due to lack of awareness, financing inability to fund tracer studies and poor preparation in terms of technical knowhow to conduct such process. For example, one of the QA coordinator had the following to say when he was asked on whether they conduct tracer studies in their institution;

"You know tracer study is one of the costly process and indeed need expertise to carry out... as you see, we most use part time lecturers and yet we have budget constrain fo fund the process and many other activities. Therefore, despite its importance, as a university we have never conducted since our establishment in 2005 (QA Director, University B).

This view is also shared by Materu (2007) who opines that the PRUs in Sub-Saharan Africa face a multitude of challenges among which is lack of financial support to fund their copious activities. This implies that tracer studies have not received as much as necessary attention in PRUs. Based on this reality, there is possibility of being unable to check the relevance of the education provided and degree programmes on offer. While funding is pointed as a critical challenge to universities in Sub-Saharan Africa, Cohen (2004) argues that tracer studies are critical in assessing relevance of the education by evaluating its quality on the world market where graduates work.

\section{Conclusion}

The present research sought to examine whether PRUs were conducting QA processes such as institutional self-assessment, external examinations, internal quality audits and tracer studies in their respective institutions. This paper has established that, QA processes such as self-assessment and external examination were conducted adequately by the surveyed Tanzanian PRUs. However, other quality assurance processes such as internal quality audits and tracer studies were not conducted adequately.

The present research further establishes that quality assurance processes were not conducted regularly in most of the surveyed Tanzanian private universities as they have been stipulated in the institutional policy documents. In view of the findings established, it is worth concluding that, operationalization of quality assurance processes as part and parcel of quality assurance mechanisms in the 
surveyed Tanzanian private universities was not implemented adequately and regularly, hence curtailing the accreditation of private universities in the country. Given these findings, it is also fair to argue that, there may be a weakness on monitoring and evaluation of the quality assurance processes by the commission charged with the responsibility of overseeing and regulating quality of education among Tanzanian universities.

\section{Implications for Quality of Education}

On the basis of the conclusions made, implementation of quality assurance processes is interpreted as one of the ways of assuring quality in education systems including higher education. Inadequacy in its operationalization of such processes implies that the quality of education may be affected to some extent. This is due to the fact that there is no adequate mechanism of checks and balances that inform the university management, the TCU and the public about quality of education offered by private universities.

Inadequacy in implementing quality assurance processes also may imply that, universities lack the sense of quality culture or the enforcement mechanisms for implementing these processes do not exist or they exist but are weak. Based on this implication, it is imperative that regulatory authorities such as TCU put in place mechanism that will enforce universities to have a compliance obligation to the set guidelines and circulars. Therefore, there is a need for the Government, through the Ministry of Education, Science and Technology, to have an explicit policy statement on QA systems so that every PRU can have effective QA systems to assure the quality of education provided. Such policy statements should be supported by an Act under the Tanzania Commission for Universities that would hold all PRUs accountable to the public in providing quality educational services.

\section{References}

Adelabu, M. A., \& Akinwumi, F. S. (2008). Factors Affecting Academic Quality in Nigeria Universities. Journal of the World Universities Forum, 1, 47-62.

Ajayi, I. A., \& Akindutire, I. O. (2007). The Unresolved Issues of Quality Assurance in Nigerian Universities. Journal of Sociology and Education in Africa, 6, 14-25.

Allais, S. M. (2009). Quality Assurance in Education. Johannesburg: Centre for Education Policy and Development.

Andy, E., \& Parker, J. (2008). Beyond Safety Management Systems, Aero Safety World. http://www.flightsafety.org/asw/may12/asw_may12_p12-17.pdf

Babyegeya, E. (2007). Splitting Large into Small Sized Primary Schools to Coexist on the Same Site: Can It Make a Difference? Journal of Issues and Practice in Education, 2, $1-11$.

Balen, R. (2010). An Evaluation Institutional Quality Assurance Practices in Netherlands Private Universities. Total Quality Management, 18, 178-190.

Banya, K. (2001). Are Private Universities the Solution to the Higher Education Crisis in Sub-Saharan Africa? Higher Education Policy, 14, 161-174.

Becket, N., \& Brookes, M. (2005). Analyzing Quality Audits in Higher Education. 
Brooke's. Journal of Learning and Teaching, 1, 1-12.

Brennan, J., \& Shah, T. (2000). Managing Quality in Higher Education. Buckingham: Society for Research into Higher Education/Open University Press.

Cohen, R. N. (2004). Introducing Tracer Studies. Guideline for Implementing Tracer Studies in Education Programmes. The Hague: Bernard van Leer Foundation.

Creswell, J. W. (2009). Mapping the Field of Mixed Methods Research. Journal of Mixed Methods Research, 3, 95-108.

Greener, I. (2011). Designing Social Research: A Guide for the Bewildered. London: SAGE Publication Ltd.

Haapakorpi, A. (2011). Quality Assurance Processes in Finnish Universities: Direct and Indirect Outcomes and Organisational Conditions. Quality in Higher Education, 17, 69-81. https://doi.org/10.1080/13538322.2011.554311

Hayward, F. M. (2006). Quality Assurance and Accreditation of Higher Education in Africa. In Conference on Higher Education Reform in Francophone Africa: Understanding the Keys of Success (pp. 1-61). Ouagadougou, Burkina Faso, June 13-15, 2006.

Idobo, M. (2009). Quality Assurance Processes: The Nature, Outcomes and Effectiveness of Quality Assurance Processes of the Catholic Education. Unpublished Doctoral thesis, Sydney: Australian Catholic University.

Ishengoma, J. M. (2007). The Debate on Quality and Private Surge: A Status Review of Private Universities and Colleges in Tanzania. Boston College \& Council for the Development of Social Science Research in Africa, 5, 85-109.

Ishengoma, J. M. (2008). Financing Public Higher Education in Tanzania: Towards a New Model and Implications for Development and Retention of the Next Generation of Academics. In The University Leaders' Forum: Next Generation of Academics, Accra, Ghana, 22-25 November, 2008.

Israel, G. D. (1992). Sampling the Evidence of Extension Program Impact. Program Evaluation and Organizational Development, IFAS, University of Florida. PEOD-5.

Kolumbia, L. (2016). Tanzania: TCU Revokes Approval to Establish Two Colleges of St. Joseph University. The Citcizen.

Kuhanga, N. H. A. (2006). Private Higher Education in Tanzania. In N. V. Varghese (Ed.), Growth and Expansion of Private Higher Education in Africa (pp. 167-202). Paris: IIEP.

Levy, D. C. (2007). Legitimacy and Privateness: Central and Eastern European Private Higher Education in Global Context. In Private Higher Education in Post-Communist Europe (pp. 279-297). New York: Palgrave Macmillan.

Materu, P. (2007). Higher Education Quality Assurance in Sub-Saharan Africa: Status, Challenges, Opportunities and Promising Practices. World Bank Working Paper No. 124, Washington DC: World Bank.

Matimbo, F. J. (2002). The Growth of Private Universities and Private Universities Colleges in Tanzania. Unpublished M. Phil. Dissertation, Oslo: University of Oslo.

Mgaiwa, S. J., \& Poncian, J. (2016). Public-Private Partnership in Higher Education Provision in Tanzania: Implications for Access to and Quality of Education. Bandung: Journal of the Global South, 3, 6. https://doi.org/10.1186/s40728-016-0036-Z

Mgaiwa, S., \& Ishengoma, J. (2017). Institutional Constraints Affecting Quality Assurance Processes in Tanzania's Private Universities. Journal of Higher Education in Africa, 15, 57-67.

Nkunya, M. H., Bienefeld, S., \& Hansert, C. (2009). Developing Internal Quality Assur- 
ance Mechanisms towards an East African Quality Assurance Framework. In European University Association (EUA): Trends in Quality Assurance. A Selection of Papers from the 3rd European Quality Assurance Forum (pp. 39-44).

OECD (2012). Quality Matters in Early Childhood Education and Care. Paris: OECD.

Okebukola, P., \& Shabani, J. (2007). Quality Assurance and Accreditation in Sub Saharan Africa: Higher Education in the World 2007, Accreditation for Quality Assurance: What Is at Stake? (2nd ed.). London: Palgrave Macmillan.

Simon, P. (2010). Academic Staff Capacities and Utilization in Private Universities in Tanzania. MEMA Dissertation, Dar es Salaam: University of Dar es Salaam.

Stensaker, B. (2008). Outcomes of Quality Assurance: A Discussion of Knowledge, Methodology and Validity. Quality in Higher Education, 14, 3-13. https://doi.org/10.1080/13538320802011532

Tanzania Commission for Universities (2012a). Universities Accreditation. http://www.tcu.tz/universities/accreditation.php.rect

Tanzania Commission for Universities (2012b). List of Registered Universities and University Colleges in Tanzania (Status by July 2012).

http://www.tcu.tz/universities/registratered.php.rect

Tanzania Commission for Universities (2015). Quality Assurance General Guidelines and Minimal Standards for Provision of University Education in Tanzania (2nd ed.). Dares Salaam: TCU.

Tanzania Commission for Universities (2016). List of Registered Universities and University Colleges in Tanzania (Status by 30 September 2016).

http://www.tcu.go.tz/images/documents/list_of_university_institutions_in_tz_as_of_30 9_2016.pdf

Thaver, L. (2006). At Home': Institutional Culture and Higher Education: Some Methodological Considerations. Perspectives in Education, 24, 15-26.

Thomas, G. (2009). How to Do Your Research Project: A Guide for Students in Education and Applied Social Sciences. London: Sage Publication Ltd.

United Republic of Tanzania (2005). Universities Act. Dar es Salaam: Government Printer.

Ursin, J., Huusko, M., Aittola, H., Kiviniemi, U., \& Muhonen, R. (2008). Evaluation and Quality Assurance in Finnish and Italian Universities in the Bologna Process. Quality in Higher Education, 14, 109-120. https://doi.org/10.1080/13538320802278222

Varghese, N. V. (2004). Private Higher Education in Africa. Geneva: International Institute for Educational Planning (IIEP), UNESCO.

Varghese, N. V. (2009). Private Sector as a Partner in Higher Education Development in Africa. Paris: UNESCO.

Varghese, N. V. (Ed.). (2006). Growth and Expansion of Private Higher Education in Africa. Geneva: UNESCO, International Institute for Educational Planning.

Yin, R. K. (2011). Qualitative Research from Start to Finish. New York: The Guilford Press. 